Supporting Information

\title{
Linear Alternating Supramolecular Photosensitizer for Enhanced Photodynamic Therapy
}

Jia Tian, $†$ Lei Xia, $†$ Jian Wu, Baoxuan Huang, Hongliang Cao, and Weian Zhang*

Shanghai Key Laboratory of Functional Materials Chemistry, School of Materials

Science and Engineering, East China University of Science and Technology, Shanghai 200237, China. 


\section{Materials and Methods}

Materials

5,10,15,20-tetrakisphenylporphyrin (TPP) and $\beta$-cyclodextrin- $\mathrm{N}_{3}$ were synthesized according our previous literature. Dichloromethane (DCM) and $N, \quad N$ dimethylformamide (DMF) were dried over calcium hydride and distilled before use. Sodium hydride (60\% dispersion in mineral oil), iodomethane, sodium ascorbate, hydroquinone, propargyl bromide, sulfate pentahydrate, trifluoroacetic acid (TFA), methoxypolyethylene glycols (average $M_{\mathrm{n}}$ 5000), sodium nitrite, stannous chloride, adamantyl chloride and hydrochloric acid were all purchased from Aladdin Reagents of China and used directly as received. 3-(4,5-Dimethylthiazol-2-yl)-2, 5diphenyltetrazolium bromide (MTT) and 4', 6-diamidino-2-phenylindole (DAPI) were purchased from Beyotime and used as received. Other reagents and solvents were purchased from Sinopharm Chemical Reagent Co. Ltd (SRC) and purified by standard procedure.

\section{Methods}

${ }^{1} \mathrm{H}$ NMR spectrum was recorded at $400 \mathrm{MHz}$, using a BRUKER AV400 Spectrophotometer, in $\mathrm{D}_{2} \mathrm{O}$ or $\mathrm{CDCl}_{3}$ with tetramethylsilane (TMS) as an internal reference. Absorption spectra were determined on a SHIMADZU UV-2550 UV spectrophotometer using in quartz Cuvette with $1 \mathrm{~cm}$ beam path length, and 
fluorescence spectra measurements were performed on a Varian's Cary Eclipse fluorescence spectrophotometer at room temperature with excitation and emission slit width of $10 \mathrm{~nm}$ and $10 \mathrm{~nm}$, respectively. MS was performed by using a XEVO G2 TOF and MALDI-TOF-mass spectra. All the measurements were carried out at room temperature.

\section{Synthesis of 5,15-bis(4-aminophenyl)-10,20-diphenylporphyrin (TPP-(NH2)2)}

TPP (0.8 g, $1.3 \mathrm{mmol})$ was added to $15 \mathrm{~mL}$ trifluoroacetic acid in a flask $(50 \mathrm{~mL})$ with a magnetic stirring bar. The solution was stirred at room temperature for 15 minutes to ensure the complete dissolution of TPP. Sodium nitrite $(0.96 \mathrm{~g}, 14 \mathrm{mmol})$ was added to the mixture and the solution was stirred for 7 minutes at room temperature. Then the reaction mixture was poured into $200 \mathrm{~mL}$ ice water to stop the reaction. The aqueous solution was extracted by DCM $(100 \mathrm{~mL})$ for three times. The organic layer was then washed by solution of $\mathrm{NaHCO}_{3}$ and dried over anhydrous $\mathrm{Na}_{2} \mathrm{SO}_{4}$. After filtration, the organic layer was concentrated and purple solid was obtained.

The nitration crude product was then put into $50 \mathrm{~mL}$ hydrochloric acid and stirred for 20 minutes at room temperature. Then $\mathrm{SnCl}_{2}(2.5 \mathrm{~g}, 13 \mathrm{mmol})$ was added to the mixture under nitrogen atmosphere. The reaction was carried out in a $70{ }^{\circ} \mathrm{C}$ oil bath for $2 \mathrm{~h}$. Water $(50 \mathrm{~mL})$ was then poured into the reaction solution and stand for $24 \mathrm{~h}$. The green precipitate was obtained by filtration and washed by ammonium hydroxide until the color of precipitate changed to purple. The obtained crude product was purified by 
column chromatography by using ethyl acetate/ petroleum ether $(1: 1, \mathrm{v} / \mathrm{v})$ as the eluent. The final product was dried under vacuum to get the purple solid $(0.15 \mathrm{~g}, 9.3 \%) .{ }^{1} \mathrm{H}$ NMR $\left(400 \mathrm{MHz}, \mathrm{CDCl}_{3}\right) \delta=8.85(\mathrm{~d}, 4 \mathrm{H}), 8.75(\mathrm{~d}, 4 \mathrm{H}), 8.14(\mathrm{~d}, 4 \mathrm{H}), 7.92(\mathrm{~d}, 4 \mathrm{H}), 7.68$ $(\mathrm{d}, 6 \mathrm{H}), 6.99(\mathrm{~d}, 4 \mathrm{H}), 3.95(\mathrm{~s}, 4 \mathrm{H}),-2.82(\mathrm{~s}, 2 \mathrm{H})$.

\section{Synthesis of TPP-Ad2}

5,15-bis(4-aminophenyl)-10,20-diphenylporphyrin (100 mg, $0.16 \mathrm{mmol}$ ) was dissolved in a mixed solution of anhydrous dichloromethane $(10 \mathrm{~mL})$ and anhydrous trimethylamine $(0.5 \mathrm{~mL})$. Adamantanecarbonyl chloride $(120 \mathrm{mg}, 0.6 \mathrm{mmol})$ was dissolved in $2 \mathrm{~mL}$ anhydrous dichloromethane and added into the reaction solution dropwise under nitrogen atmosphere. The reaction solution was stirred at room temperature for $24 \mathrm{~h}$. The solution was washed by saturated aqueous solution of $\mathrm{NaCl}$ for three times and concentrated to give crude product. The crude product was purified by column chromatography using ethyl acetate/ petroleum ether $(1: 3, \mathrm{v} / \mathrm{v})$ as the eluent. The final product was dried under vacuum to afford a purple solid (110 mg, 70\%). ${ }^{1} \mathrm{H}$ NMR $\left(400 \mathrm{MHz}, \mathrm{CDCl}_{3}\right) \delta=8.87-8.66(\mathrm{~m}, 8 \mathrm{H}), 8.18-8.02(\mathrm{~m}, 8 \mathrm{H}), 7.89(\mathrm{dd}, 4 \mathrm{H})$, 7.74 - $7.62(\mathrm{~m}, 6 \mathrm{H}), 2.13$ (s, 6H), 2.06 (s, 12H), 1.76 (d, 12H). LRESIMS: m/z 969.51 $[\mathrm{M}+\mathrm{H}]^{+}(100 \%)$.

\section{Synthesis of S1}

A flask $(100 \mathrm{~mL})$ was charged with a magnetic stirring bar. Hydroquinone (1.0 g, 9 mmol), propargyl bromide (3.2 g, $27 \mathrm{mmol}), \mathrm{K}_{2} \mathrm{CO}_{3}(3.40 \mathrm{~g}, 24.15 \mathrm{mmol})$, and $50 \mathrm{~mL}$ 
acetonitrile were added to the flask under a nitrogen atmosphere. The reaction was conducted in a $60{ }^{\circ} \mathrm{C}$ oil bath and stirred for $24 \mathrm{~h}$. Then the solvent was evaporated under reduced pressure and the residue was dissolved in dichloromethane. Saturated solution of sodium chloride was used to wash organic layer three times. Then organic layer was separated, dried over anhydrous $\mathrm{MgSO}_{4}$ and concentrated in vacuo. The crude product was purified by column chromatography on silica gel by using dichloromethane/petroleum ether $(1: 1, \mathrm{v} / \mathrm{v})$ as the eluent. The final product was dried under vacuum at room temperature for $24 \mathrm{~h}$ to give $\mathbf{S 1}$ as a yellow solid (1.4 g, 85\%).

\section{Synthesis of permethyl- $\beta$-cyclodextrin- $\mathrm{N}_{3}\left(\mathrm{CD}-\mathrm{N}_{3}\right)$}

$\beta$-cyclodextrin- $\mathrm{N}_{3}(0.2 \mathrm{~g}, 0.17 \mathrm{mmol})$ was dissolved in anhydrous DMF $(15 \mathrm{~mL})$ in a $50 \mathrm{~mL}$ flask. The flask was cooled to $0{ }^{\circ} \mathrm{C}$ in an ice water bath. Sodium hydride $(0.18$ g, $4.5 \mathrm{mmol}$ ) was slowly added to solution under nitrogen atmosphere. After stirring for $1 \mathrm{~h}$ at room temperature, iodomethane $(0.91 \mathrm{~g}, 6.4 \mathrm{mmol})$ in $10 \mathrm{~mL}$ anhydrous DMF was added dropwise. The reaction solution was stirred for $24 \mathrm{~h}$ at room temperature. Then water $(50 \mathrm{~mL})$ was added dropwise to quench unreacted sodium hydride and ethyl acetate $(50 \mathrm{~mL} \times 3)$ was used to extract the product. The organic phase was concentrated under vaccum to give permethyl- $\beta$-cyclodextrin- $\mathrm{N}_{3}$ as a pale yellow solid (166 mg, 70\%). LRESIMS: $\mathrm{m} / \mathrm{z} 1462.63[\mathrm{M}+\mathrm{Na}]^{+}(100 \%)$. 


\section{Synthesis of permethyl- $\beta$-cyclodextrin-dimer $\left(\mathrm{CD}_{2}\right)$}

$\mathrm{CD}^{-\mathrm{N}_{3}}(1.0 \mathrm{~g}, 0.7 \mathrm{mmol}), \mathrm{S} 1(0.04 \mathrm{~g}, 0.23 \mathrm{mmol})$ and sodium ascorbate $(0.2 \mathrm{~g}, 1 \mathrm{mmol})$ was dissolved in $30 \mathrm{~mL} \mathrm{DMF}$. $\mathrm{CuSO}_{4} \cdot 5 \mathrm{H}_{2} \mathrm{O}(0.18 \mathrm{~g}, 0.7 \mathrm{mmol})$ in $5 \mathrm{~mL}$ deionized water was added to the solution under nitrogen atmosphere. The reaction solution was stirred in a $60{ }^{\circ} \mathrm{C}$ oil bath for $24 \mathrm{~h}$. Then the solution was concentrated in vacuo and the residue was dissolved in $\mathrm{CHCl}_{3}$. The $\mathrm{CHCl}_{3}$ was washed by saturated $\mathrm{NaCl}$ solution and concentrated. The crude product was purified by column chromatography on silica gel by using dichloromethane/methanol $(50: 1, \mathrm{v} / \mathrm{v})$ as the eluent. Final product was obtained under vacuum for $24 \mathrm{~h}$ to give $\mathrm{CD}_{2}$ as a yellow solid (180 mg, 25\%).

\section{Synthesis of permethyl- $\beta$-cyclodextrin (CD)}

The synthesis method of $\mathrm{CD}$ was similar to that of $\mathrm{CD}-\mathrm{N}_{3}$. The final product was obtained with a yield of 80\%. LRESIMS: m/z $1451.67[\mathrm{M}+\mathrm{Na}]^{+}(100 \%)$.

\section{Synthesis of PEG-Ad}

Methoxypolyethylene glycols $(1.0 \mathrm{~g}, 0.2 \mathrm{mmol})$ was dissolved in anhydrous toluene $(20 \mathrm{~mL})$ and refluxed overnight at $90{ }^{\circ} \mathrm{C}$. After the traces of water were removed by azeotropic distillation, toluene was evaporated at reduced pressure. Then methoxypolyethylene glycols was dissolved in anhydrous DCM and the solution was cooled down to $0{ }^{\circ} \mathrm{C}$. Anhydrous trimethylamine $(0.5 \mathrm{~mL})$ and adamantoyl chloride $(0.4$ $\mathrm{g}, 2 \mathrm{mmol}$ ) in $5 \mathrm{~mL}$ anhydrous trimethylamine was added to solution dropwise under nitrogen atmosphere. The reaction was allowed to stir at room temperature for $24 \mathrm{~h}$. 
After filtration, the solution was precipitated in cold diethyl ether for three times. The final product was obtained under vacuum to give PEG-Ad as a white solid (0.77 g, $75.3 \%)$

Investigation of the interactions between TPP-Ad2 and $\mathrm{CD}_{2}$

\section{NMR titration experiments}

NMR titration experiment was utilized to study the complexation between TPP-Ad 2 and $\mathrm{CD}_{2}$. A d-DMSO/ $\mathrm{D}_{2} \mathrm{O}(1 / 100, \mathrm{v} / \mathrm{v})$ mixed solvent was used due to the poor solubility of TPP- $\mathrm{Ad}_{2}$ in $\mathrm{D}_{2} \mathrm{O}$. In this mixed solvent, TPP- $\mathrm{Ad}_{2}$ had a constant molar concentration of $5 \mathrm{mM}$ and $\mathrm{CD}_{2}$ had a varying concentration of $2.5,5$ and $10 \mathrm{mM}$. The NMR titration experiment was performed on the BRUKER AV400 Spectrophotometer (400 MHz).

\section{Fluorescence titration experiments}

Fluorescence spectrum was also used to investigate the host-guest complexation between host molecule and guest molecule. TPP-Ad 2 had a constant concentration of $1 \times 10^{-5} \mathrm{M}$ in a $\mathrm{DMSO} / \mathrm{H}_{2} \mathrm{O}(1 / 100, \mathrm{v} / \mathrm{v})$ mixed solution, while $\mathrm{CD}_{2}$ had a varying

concentration $\left(0,0.25,0.5,0.75,1.0,2.0,3.0\right.$, and $\left.4.0 \times 10^{-5} \mathrm{M}\right)$. The complexation constant $K_{a}$ was calculated by a non-linear curve-fitting method.

Similar procedure was used to study the complexation between TPP-Ad 2 and CD. 


\section{UV-vis titration experiments}

The changes of UV-vis spectrum of TPP- $\mathrm{Ad}_{2} / \mathrm{CD}_{2}$ complexes were used to study the host-guest complexation behavior. A DMSO/ $\mathrm{H}_{2} \mathrm{O}(1 / 100, \mathrm{v} / \mathrm{v})$ mixed solution, where TPP-Ad $\mathrm{Ad}_{2}$ had a constant concentration of $5 \times 10^{-5} \mathrm{M}$ and $\mathrm{CD}_{2}$ had a varying concentration $\left(0,1.25,2.5,3.75,5.0,10.0,15.0,20.0 \times 10^{-5} \mathrm{M}\right)$, was recorded on a $\mathrm{UV}$-vis spectrometer.

Self-assembly of the TPP-Ad $/$ CD, TPP-Ad $/ \mathrm{CD}_{2}$ and TPP-Ad $/ \mathrm{CD}_{2} / \mathrm{PEG}-\mathrm{Ad}$ complexes in aqueous solution

TPP-Ad $2(0.97 \mathrm{mg}, 0.001 \mathrm{mmol})$ and CD $(2.86 \mathrm{mg}, 0.002 \mathrm{mmol})$ were dissolved in 0.3 $\mathrm{mL}$ DMSO and stirred for $2 \mathrm{~h}$ at room temperature. Under vigorous stirring, deionized water $(0.7 \mathrm{~mL})$ was added to the solution dropwise in 30 minutes. The mixed solution was maintained at $25^{\circ} \mathrm{C}$ water bath with stirring. After that, DMSO was removed by dialysis (MWCO $12 \mathrm{kDa}$ ) against deionized water (changing water for 3 times). The final concentration of this assembled solution was determined to be $0.81 \mathrm{mg} / \mathrm{mL}$ (calculated by TPP concentration).

TPP-Ad $2(0.97 \mathrm{mg}, 0.001 \mathrm{mmol})$ and $\mathrm{CD}_{2}(3.1 \mathrm{mg}, 0.001 \mathrm{mmol})$ were used to prepare TPP- $-\mathrm{Ad}_{2} / \mathrm{CD}_{2}$ complex with the similar method above. The final concentration of this assembled solution was determined to be $0.81 \mathrm{mg} / \mathrm{mL}$ (calculated by TPP concentration).

TPP-Ad $2 / \mathrm{CD}_{2} /$ PEG-Ad complex was constructed by adding a small amount of PEGAd $(0.5 \mathrm{mg}, 0.0001 \mathrm{mmol})$ to TPP- $\mathrm{Ad}_{2} / \mathrm{CD}_{2}$ mixed solution. DMSO and free PEG-Ad 
was removed by dialysis (MWCO $12 \mathrm{kDa}$ ) against deionized water (changing water for 3 times). The final concentration of this assembled solution was determined to be 0.81 $\mathrm{mg} / \mathrm{mL}$ (calculated by TPP concentration).

\section{Singlet oxygen measurement}

Typically, 1,3-diphenylisobenzofuran (DPBF) was used as a chemical ${ }^{1} \mathrm{O}_{2}$ probe in a DMSO/ $\mathrm{H}_{2} \mathrm{O}(1: 100, \mathrm{v} / \mathrm{v})$ mixed solution (1\% DMSO was used to improve solubility of DPBF). The concentration of four sample solution are as follow:

TPP- $\mathrm{Ad}_{2}$ in mixed solution

TPP- $-\mathrm{Ad}_{2}=1.0 \times 10^{-5} \mathrm{M}$

TPP-Ad $/$ CD complex in mixed solution

$\mathrm{TPP}-\mathrm{Ad}_{2}=1.0 \times 10^{-5} \mathrm{M}, \mathrm{CD}=2.0 \times 10^{-5} \mathrm{M}$

$\mathrm{TPP}-\mathrm{Ad}_{2} / \mathrm{CD}_{2}$ complex in mixed solution

$\mathrm{TPP}-\mathrm{Ad}_{2}=1.0 \times 10^{-5} \mathrm{M}, \mathrm{CD}_{2}=1.0 \times 10^{-5} \mathrm{M}$

TPP-Ad $/ \mathrm{CD}_{2} / \mathrm{PEG}-\mathrm{Ad}$ complex in mixed solution

TPP- $\mathrm{Ad}_{2}=1.0 \times 10^{-5} \mathrm{M}, \mathrm{CD}_{2}=1.0 \times 10^{-5} \mathrm{M}, \mathrm{PEG}-\mathrm{Ad}=0.1 \times 10^{-5} \mathrm{M}$

\section{Cell Culture}

4T1 cells were routinely incubated in Dulbecco's modified Eagle's medium (DMEM) supplied with 50 units/mL (penicillin and streptomycin) and $10 \%$ fetal bovine serum 
(FBS) in a humidified standard atmosphere of $5 \% \mathrm{CO}_{2}$ at $37{ }^{\circ} \mathrm{C}$.

\section{Cellular Uptake Studies}

The cellular uptake experiments were carried out by flow cytometry and confocal laser scanning microscope (CLSM). Flow cytometry was used to set up statistics on the uptake of complexes into 4T1 cells. The 4T1 cells were seeded in six well flat culture plates with a cell density of $1 \times 10^{4}$ cells per well. After $24 \mathrm{~h}$ of culture, culture medium was replaced by DMEM containing the samples and treated for $4 \mathrm{~h}$ and $24 \mathrm{~h}$, respectively. After the predetermined time, the cells were trypsinized and washed with PBS solution. Then the cells were suspended in PBS for determining the fluorescence intensity on a BD FACS Calibur flow cytometer.

For CLSM measurement, 4T1 cells were cultured in $2 \mathrm{~mL}$ culture medium on polylysine-coated glass slides inside $30 \mathrm{~mm}$ glass culture dishes and allowed to grow to $50-70 \%$ at $37{ }^{\circ} \mathrm{C}$. Afterward, cells (on glass slides) were washed with PBS, and reincubated in DMEM medium containing the samples at $37{ }^{\circ} \mathrm{C}$ under $5 \% \mathrm{CO}_{2}$ for 24 h. After predetermined time, the culture medium was removed and washed with PBS three times. Subsequently, the 4, 6-diamidino-2-phenylindole (DAPI) was added to stain the nuclei for $3 \mathrm{~min}$. The cells were imaged directly via CLSM after washing with PBS three times.

\section{In vitro dark cytotoxicity}

The cytotoxicity of various samples in 4T1 cells was determined via MTT assay. The 
cells were seeded in 96-well plates at the cell population of about 5000 cells/well in $200 \mu \mathrm{L}$ DMEM. After $24 \mathrm{~h}$ of incubation in 96-well plates at $37^{\circ} \mathrm{C}$, samples with various concentrations were added to each well. All the samples were then subjected to incubation for $24 \mathrm{~h}$. Then, the wells were incubated for another $4 \mathrm{~h}$ with RPMI 1640 medium containing $5 \mathrm{mg} \mathrm{mL}^{-1}$ MTT. After discarding the culture medium, $150 \mu \mathrm{L}$ DMSO was added to each well to extract the formazan products with gentle agitation for $10 \mathrm{~min}$. The absorbance at $492 \mathrm{~nm}$ was measured using a spectrophotometric microplate reader (Thermo Multiskan MK3 spectrometer). The cell viability was calculated as follows: cell viability $(\%)=\left(\mathrm{OD}_{\text {test }}\right) /\left(\mathrm{OD}_{\text {control }}\right) \times 100$, where $\mathrm{OD}_{\text {test }}$ is the absorbance in the presence of sample solutions and $\mathrm{OD}_{\text {control }}$ is the absorbance without treatment.

\section{In Vitro Phototoxicity}

Similar procedure was used to evaluate the phototoxicity of samples. After $4 \mathrm{~h}$ of incubation, the plate with cells was irradiated with a $660 \mathrm{~nm}$ laser light for $20 \mathrm{~min}$. The cells were then incubated at $37^{\circ} \mathrm{C}$ for $24 \mathrm{~h}$, and the cell viability was also estimated using the MTT assay as described above.

\section{Animals and tumor models}

All animal experiments were approved by the regional animal committee and were in accordance with international guidelines on the ethical use of laboratory animals. Female BALB/c nude mice (4- to 6-week-old) were maintained in a pathogen free 
environment under controlled temperature $\left(24^{\circ} \mathrm{C}\right)$. The female nude mice were injected subcutaneously in the right leg region with $100 \mu \mathrm{L}$ of cell suspension containing $2 \times$ $10^{6} 4 \mathrm{~T} 1$ cells. The tumors were allowed to grow to $\sim 70 \mathrm{~mm}^{3}$ before experimentation. The tumor volume was calculated as (tumor length) $\times(\text { tumor width })^{2} / 2$.

\section{In Vivo Photodynamic Therapy}

When the tumor volume reached about $100 \mathrm{~mm} 3$, tumor-bearing mice were divided into seven groups ( $n=5$ mice/group) randomly for different formulations: (1) saline alone; (2) saline + light; (3) TPP-Ad2 $/ \mathrm{CD}_{2} /$ PEG-Ad; (4) TPP-Ad + light; (5) TPP$\mathrm{Ad}_{2} / \mathrm{CD}+$ light; (6) TPP-Ad $/ \mathrm{CD}_{2}+$ light; (7) TPP-Ad $/ \mathrm{CD}_{2} / \mathrm{PEG}-\mathrm{Ad}+$ light. The solution of different groups $(200 \mu \mathrm{L}, 1 \mathrm{mg} / \mathrm{mL})$ was intravenously injected into mice and irradiated by the $660 \mathrm{~nm}$ laser $\left(0.5 \mathrm{~W} \mathrm{~cm}^{-2}\right)$ for $10 \mathrm{~min}$ after $12 \mathrm{~h}$. The tumor dimensions (length and width) and body weight were measured every two days after the treatment. The mice were sacrificed after 12 days post-treatment, the tumors were collected, and photos were taken.

\section{In Vivo Fluorescence Imaging}

When the tumors grew to about $70 \mathrm{~mm}^{3}$, the five mice were treated with the solution of TPP-Ad $2 / \mathrm{CD}_{2} / \mathrm{PEG}-\mathrm{Ad}(200 \mu \mathrm{L}, 1 \mathrm{mg} / \mathrm{mL})$ via the tail vein. The fluorescence images of mice were taken 1 h, 3 h, 6 h, 12 h and 24 h after injection, respectively. 


\section{Tissue Immunohistological Evaluation}

In the histological assay, the heart, liver, spleen, lung, kidney and tumor tissues were fixed in $4 \%$ paraformaldehyde for $24 \mathrm{~h}$. The specimens were dehydrated in graded ethanol, embedded in paraffin, and cut into $5 \mathrm{~mm}$ thick sections. The fixed sections were deparaffinized and hydrated according to a standard protocol and stained with hematoxylin and eosin (H\&E) for microscopic observation.

\section{Statistical Analysis}

Student's $t$-test was used for statistical analysis. The statistically significant difference between different groups was marked as $* p$, $* * p$, and $* * * p$ for $p<0.01,0.05$, and 0.001 , respectively. 


\section{Schemes and Figures}
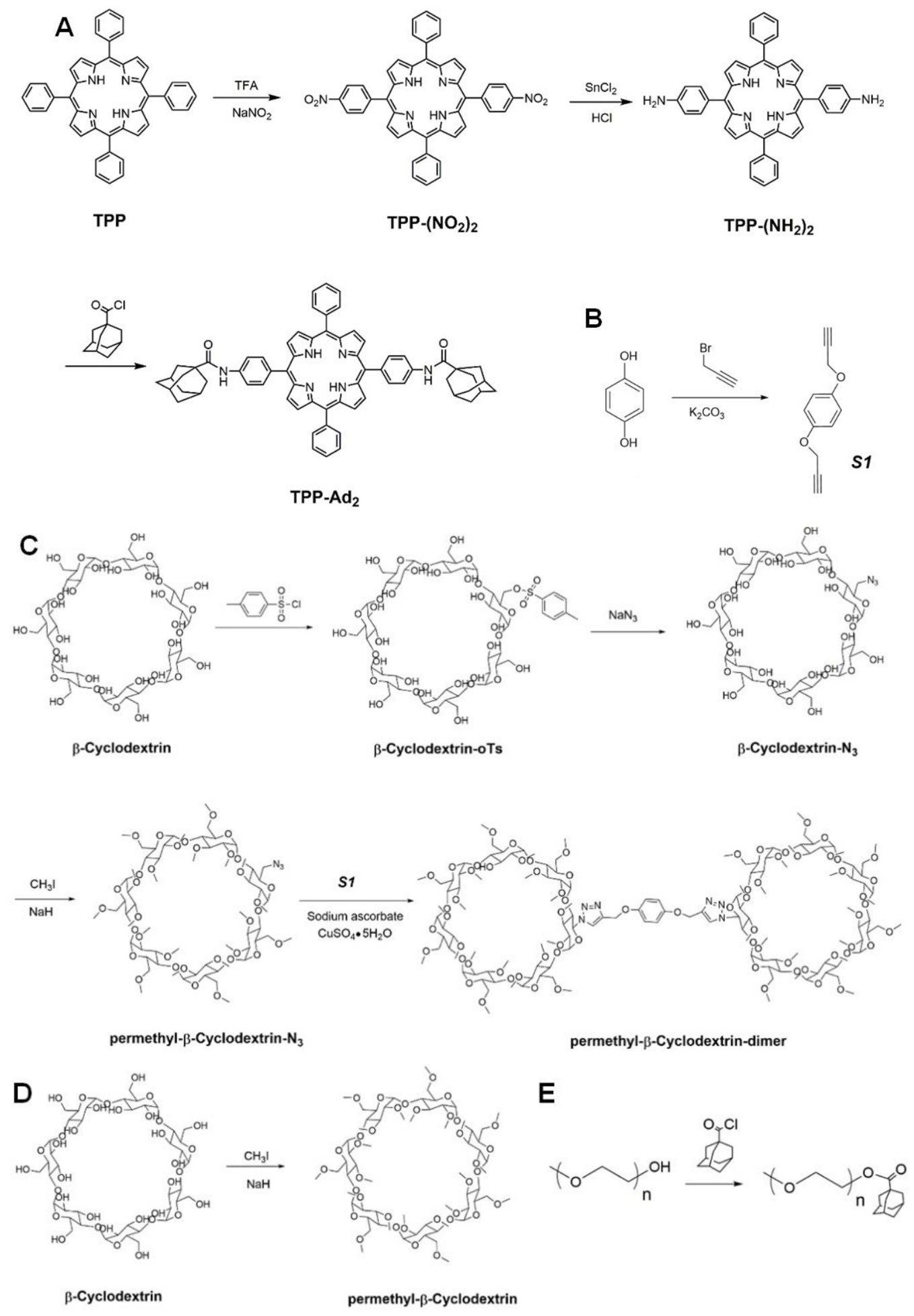

Scheme S1. Synthesis of (A)TPP-Ad2, (B) S1, (C) permethyl- $\beta$-cyclodextrin-dimer (CD2), (D) permethyl- $\beta$-cyclodextrin (CD), (E) PEG-Ad. 

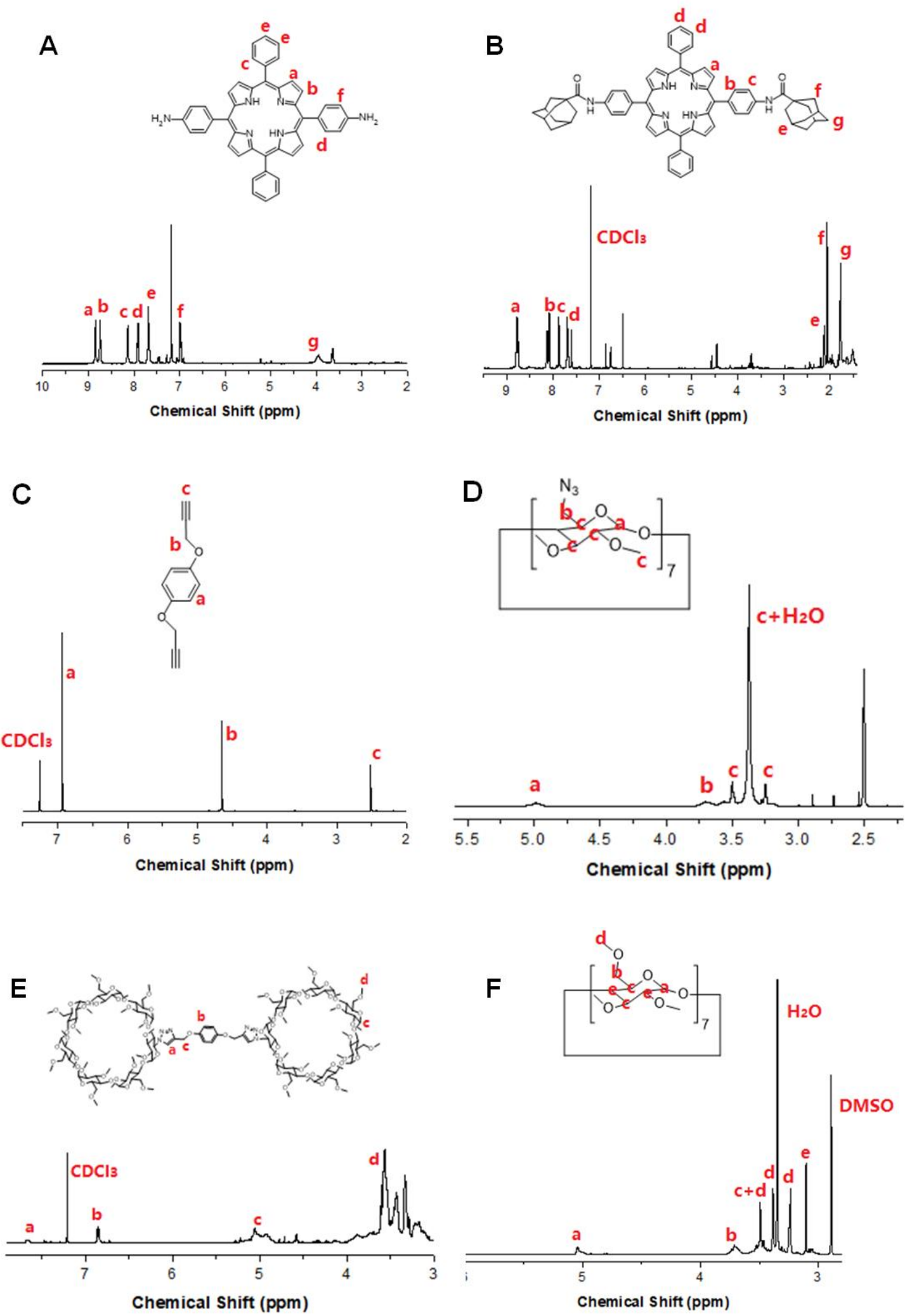


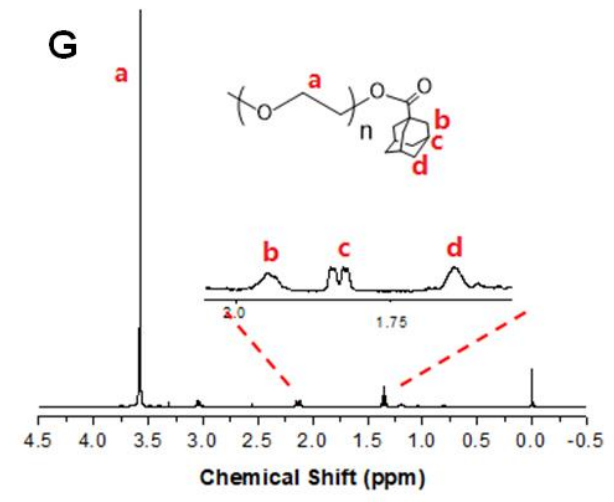

Figure S1. ${ }^{1} \mathrm{H}$ NMR spectra of (A)TPP-(NH2)2, (B) TPP-Ad2, (C) S1, (D) CD-N3, (E) CD 2 , (F) CD, (G) PEG-Ad.

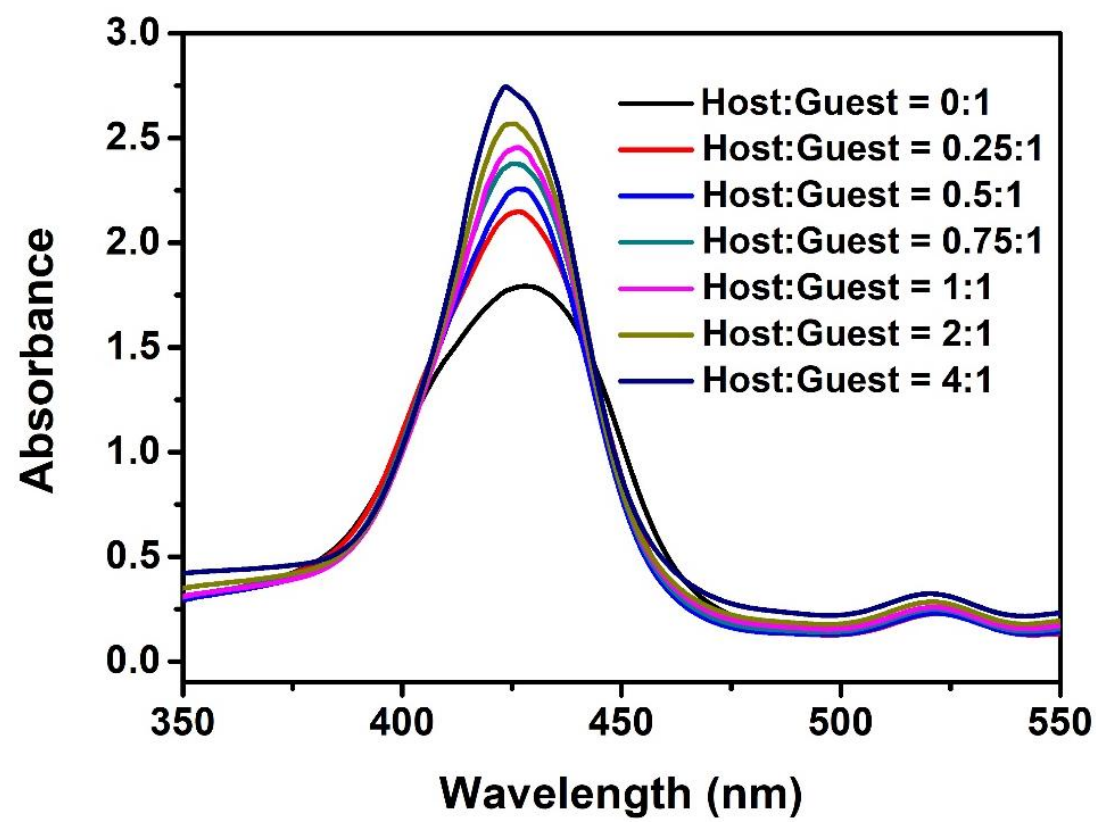

Figure S2. UV-vis absorption spectra of TPP- $\mathrm{Ad}_{2}\left(5.0 \times 10^{-5} \mathrm{M}\right)$ in aqueous solution with different concentrations of $\mathrm{CD}_{2}\left(0,1.25,2.5,3.75,5.0,10.0,20.0 \times 10^{-5} \mathrm{M}\right)$. 

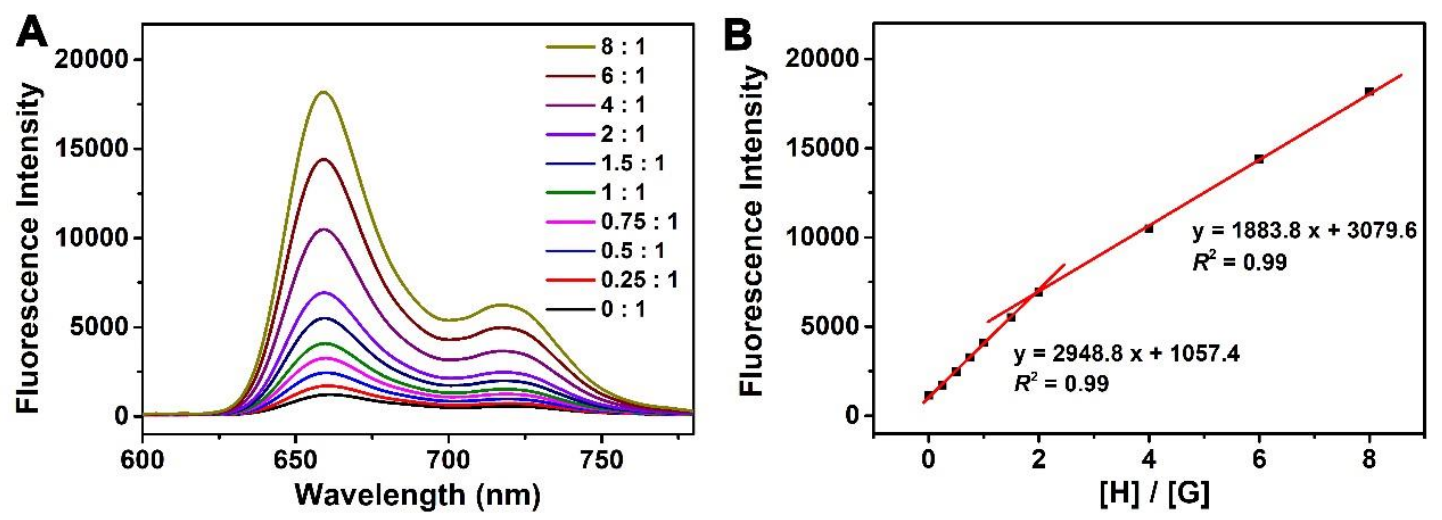

Figure S3. (A) The fluorescence intensity variation of TPP-Ad $2\left(1 \times 10^{-5} \mathrm{M}\right)$ upon addition of $\mathrm{CD}\left(0,0.25,0.5,0.75,1,1.5,2,4,6\right.$ and $\left.8 \times 10^{-5} \mathrm{M}\right)$ in aqueous solution. (B) Molar ratio plots for TPP- $\mathrm{Ad}_{2}$ and $\mathrm{CD}$ from the maximum absorbance at the wavelength of $659 \mathrm{~nm}$, indicating a 1:2 stoichiometric ratio.
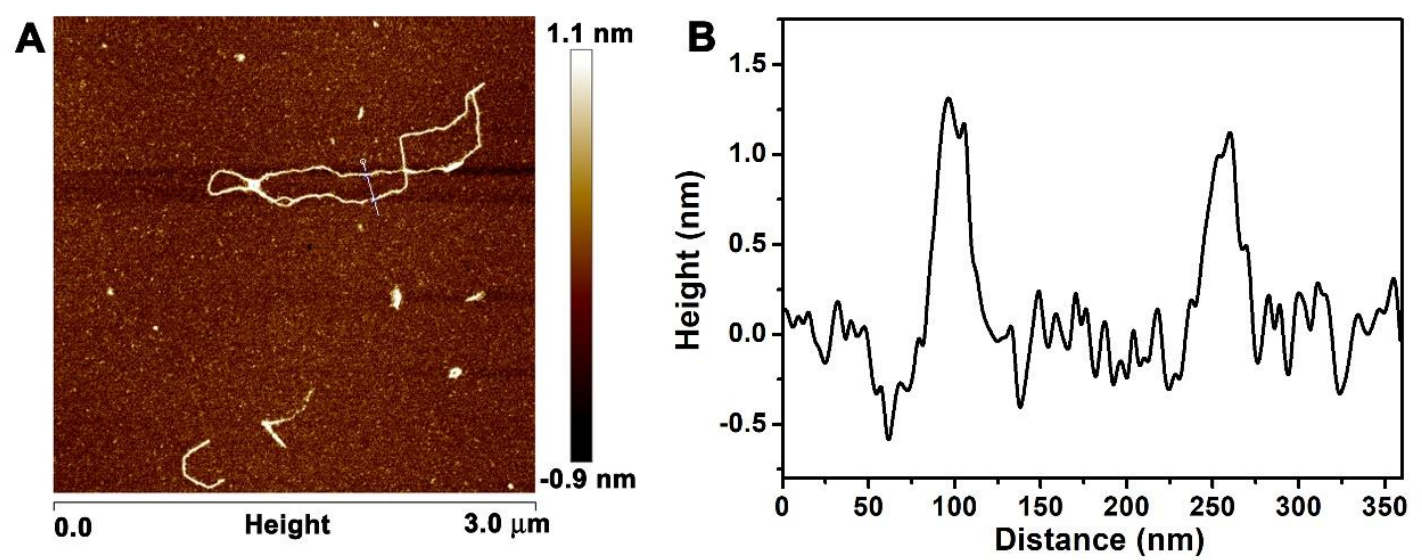

Figure S4. (A) AFM image of TPP- $\mathrm{Ad}_{2} / \mathrm{CD}_{2}$ complexes in aqueous solution. (B) The height plots of selected region in (A). 


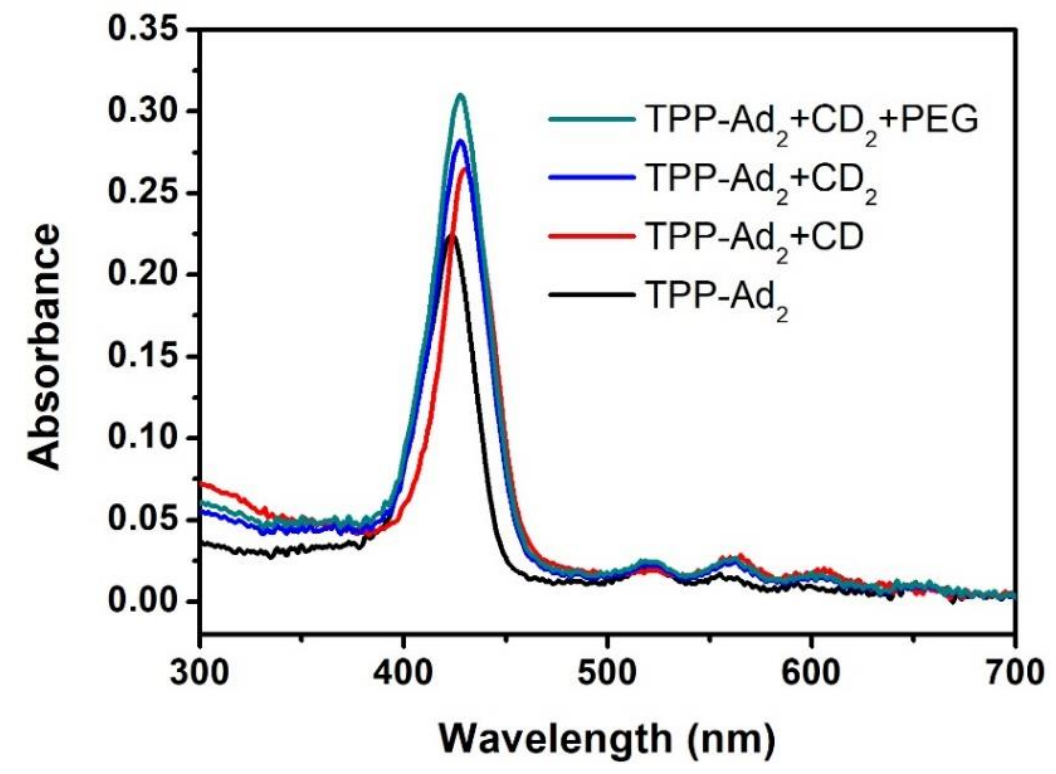

Figure S5. UV-vis spectra of TPP- $A d_{2} / C D, T P P-A d_{2} / C D_{2}$ and $T P P-A d_{2} / C D_{2} / P E G$ in aqueous solution, TPP- $\mathrm{Ad}_{2}$ in $\mathrm{DMF} / \mathrm{H}_{2} \mathrm{O}$ 1:100 solution.

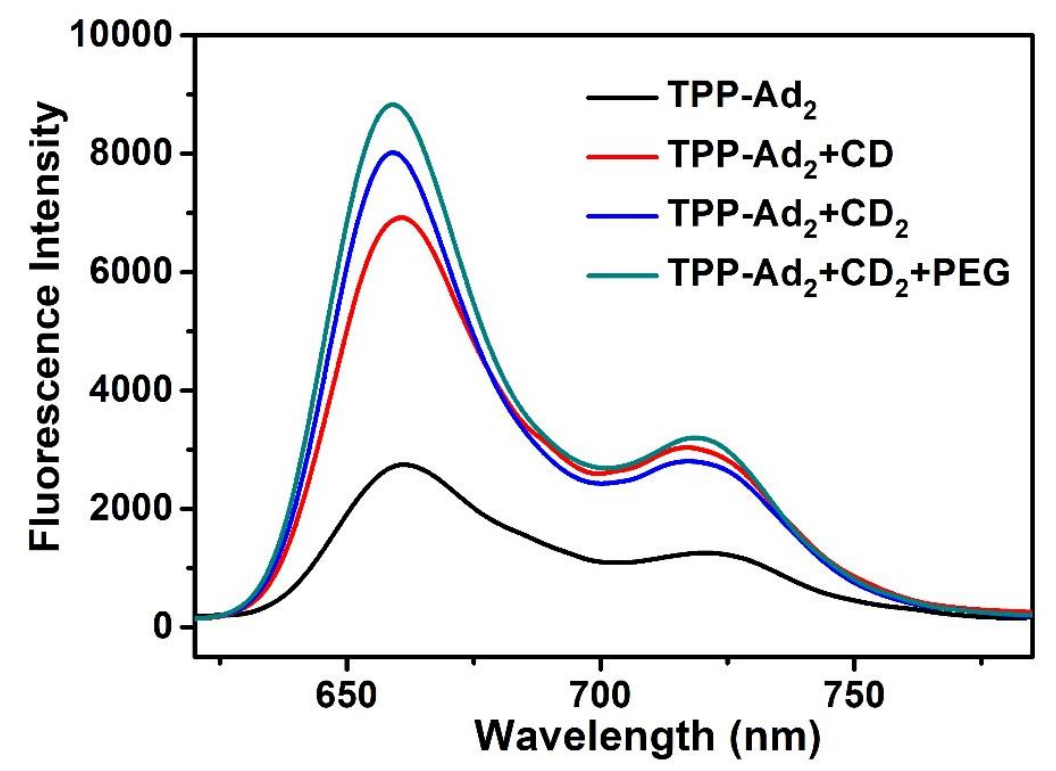

Figure S6. Fluorescence spectra of TPP-Ad 2 aggregates, TPP- $\mathrm{Ad}_{2} / \mathrm{CD}$ complexes, TPP- $\mathrm{Ad}_{2} / \mathrm{CD}_{2}$ complexes and TPP- $\mathrm{Ad}_{2} / \mathrm{CD}_{2} / \mathrm{PEG}$ complexes in aqueous solution at room temperature. 

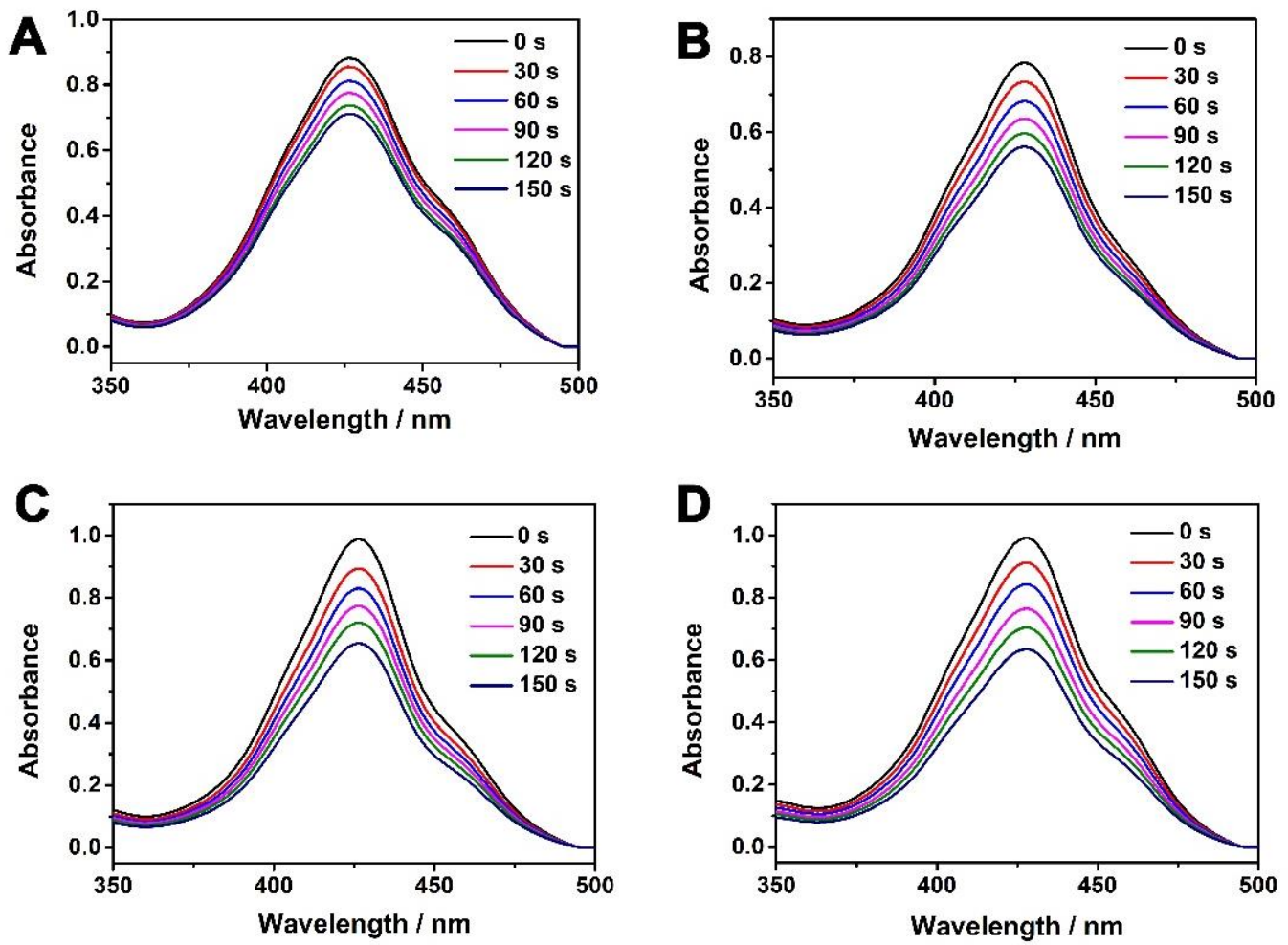

Figure S7. UV-Vis spectra changes of DPBF in the solution of (A) TPP-Ad 2 , (B) TPP$\mathrm{Ad}_{2} / \mathrm{CD}$, (C) TPP-Ad $/ \mathrm{CD}_{2}$, and (D) TPP-Ad $/ \mathrm{CD}_{2} / \mathrm{PEG}-\mathrm{Ad}$ under a $660 \mathrm{~nm}$ laser light, respectively.

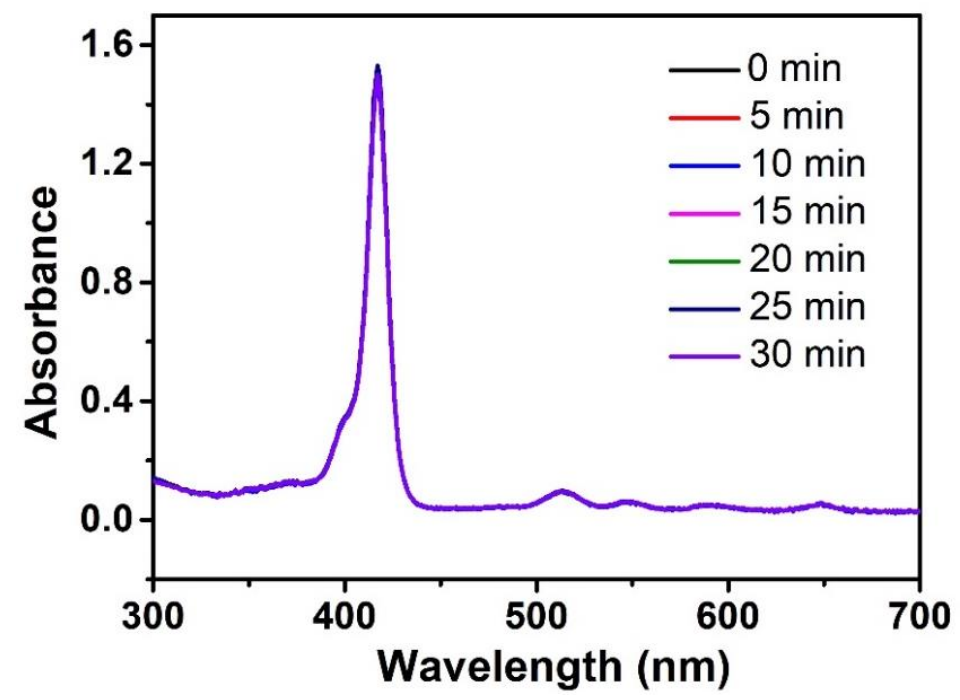

Figure S8. The photostability of TPP-Ad 2 in DMF solution measured by UV-vis under $660 \mathrm{~nm}$ light irradiation for different irradiation dosages. 


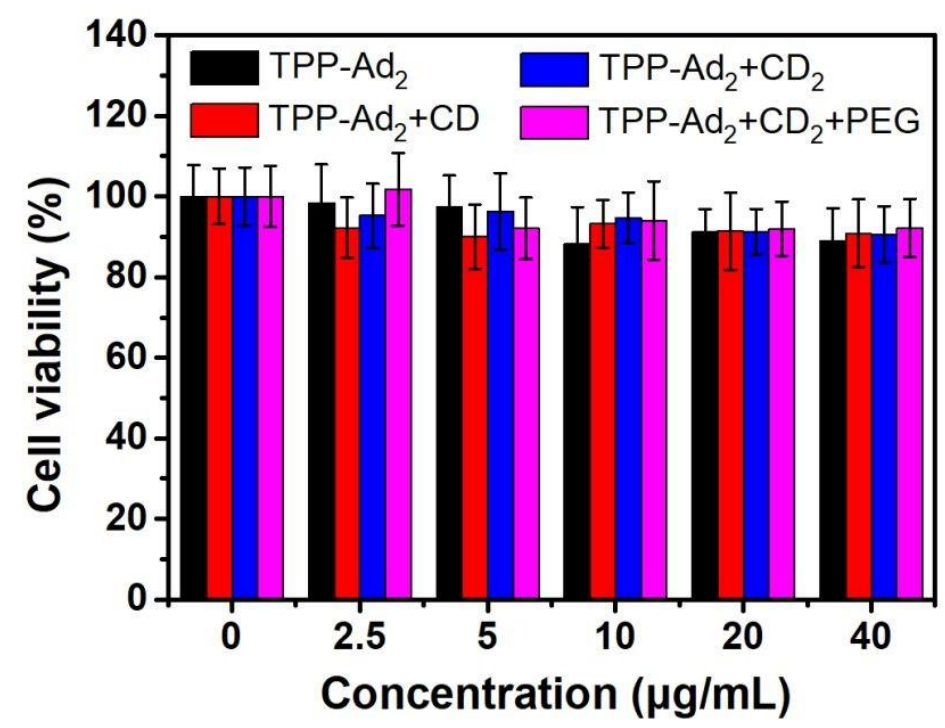

Figure S9. In vitro dark cytotoxicity of $\mathrm{TPP}-\mathrm{Ad}_{2}, \mathrm{TPP}-\mathrm{Ad}_{2} / \mathrm{CD}$ complexes, TPP$\mathrm{Ad}_{2} / \mathrm{CD}_{2}$ and TPP-Ad $/ \mathrm{CD}_{2} / \mathrm{PEG}$ linear supramolecular polymers toward HEK293 cells.

(A)

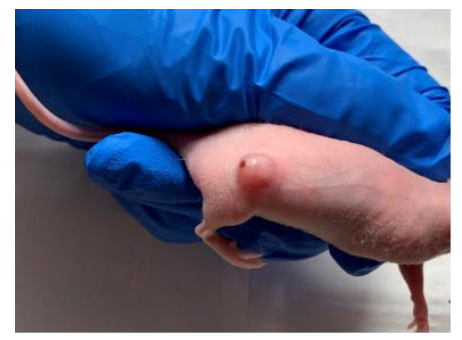

(B)

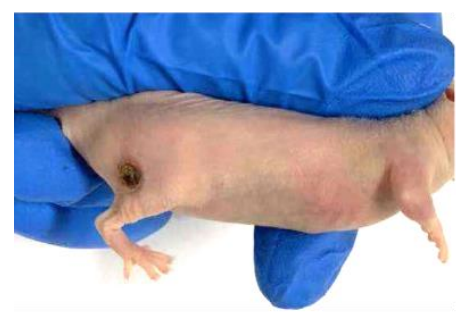

Figure S10. Images of tumor-bearing nude mice before and after treatment of TPP$\mathrm{Ad}_{2} / \mathrm{CD}_{2} / \mathrm{PEG}-\mathrm{Ad}$ solution: (A) 0 day and (B) $12^{\text {th }}$ day. 


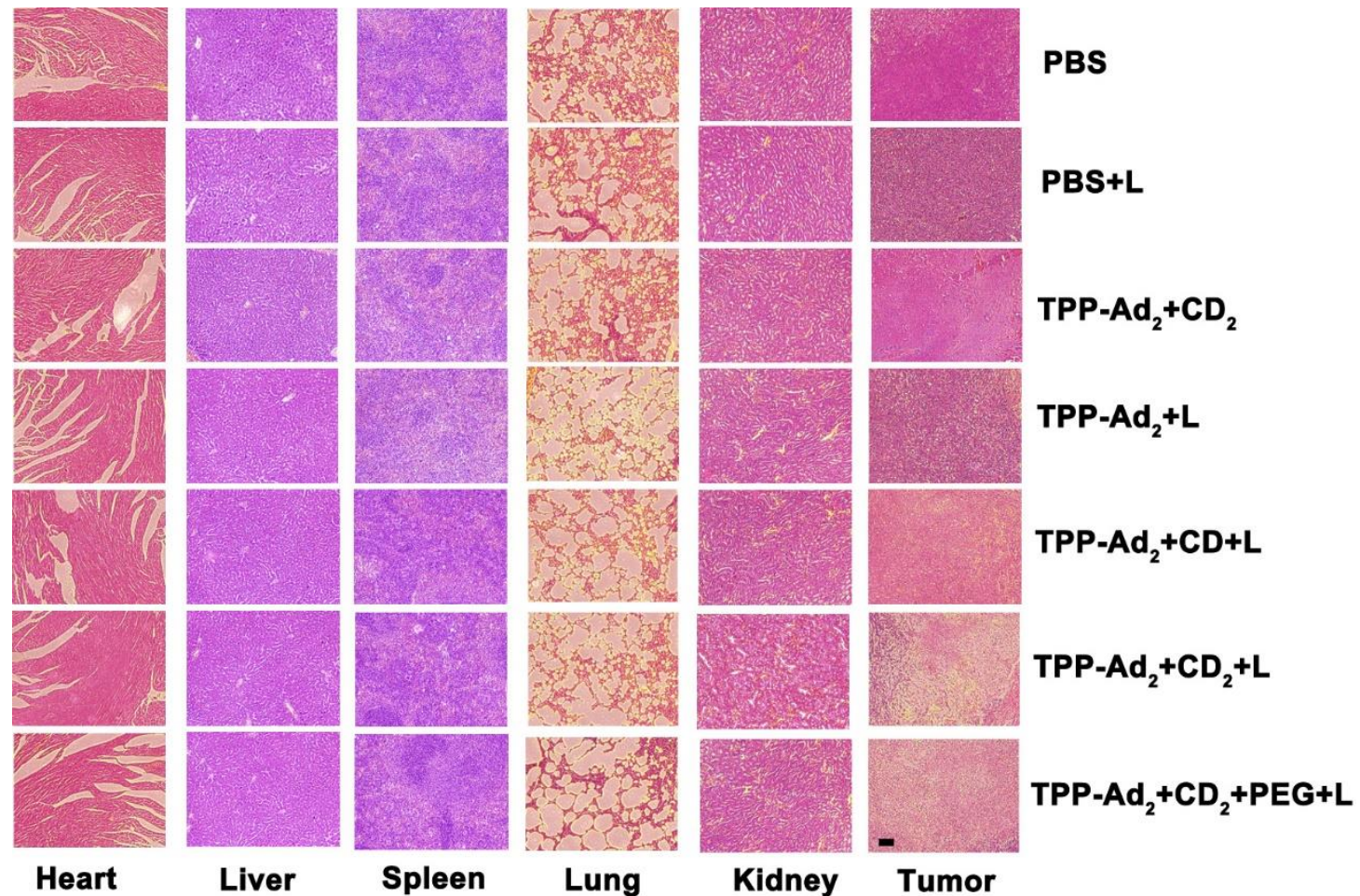

Figure S11. Micrographs of H\&E stained major organs and tumor slices. Scale bar 100 $\mu \mathrm{m}$. 